\title{
A randomised feasibility study assessing an intervention to keep adults physically active after falls management exercise programmes end
}

\author{
Sarah Audsley ${ }^{1 *} \mathbb{D}$, Denise Kendrick', Pip Logan², Matthew Jones ${ }^{1}$ and Elizabeth Orton ${ }^{1}$
}

\begin{abstract}
Background: Physical inactivity contributes to disability and falls in older adults. Falls prevention exercise (FaME) programmes improve physical activity and physical function and reduce falling rates. Improvements in physical function are reduced, and falls rates increase, if physical activity is not maintained. This research investigated the feasibility and acceptability of an intervention that aimed to maintain physical activity in older adults exiting FaME.

Methods: The Keeping Adults Physically Active (KAPA) intervention comprised of six group sessions of motivational interviewing, delivered monthly by trained and mentor-supported postural stability instructor's after the FaME programme ceased. The KAPA intervention included participant manuals, illustrated exercise books, physical activity diaries and pedometers. A feasibility study was conducted in 8 FaME classes. The study design was a two-arm, cluster randomised, multi-site feasibility study comparing the KAPA intervention with usual care. A sample of 50 community-dwelling adults aged 65 years old or older were recruited. Recruitment, retention and attendance rates, self-reported physical activity and participant interviews were used to examine the feasibility and acceptability of the KAPA intervention.
\end{abstract}

Results: Fifty of the sixty-seven (74.6\%) participants invited into the study agreed to take part, $94.2 \%$ of the available KAPA sessions were attended and $92.3 \%$ of the recruited participants provided outcome data. The KAPA participants expressed positive views about the venues and postural stability instructors and reported enjoying the group interactions. Intervention participants discussed increasing their physical activity in response to the peersupport, illustrated home exercise booklet, physical activity diaries and pedometers. Most discussed the written tasks to be the least enjoyable element of the KAPA intervention. The proportion of participants reporting at least 150 minutes of moderate to vigorous physical activity per week rose from 56.3 to $62.5 \%$ in the intervention arm and from 41.4 to $52.0 \%$ in the usual care arm.

Conclusions: The participants found the KAPA intervention acceptable. Participants reported the exercise booklet, peer support and the physical activity monitoring tools encouraged them to keep active. A full-scale trial is needed to assess whether physical activity can be significantly maintained in response to the KAPA intervention.

Trial registration: Retrospectively registered on ClinicalTrials.gov (NCT03824015).

Keywords: Older adults, Physical activity, Falls prevention, Feasibility study

\footnotetext{
*Correspondence: sarah.audsley_nottingham.uk.ac@outlook.com

'Division of Primary Care, University of Nottingham, Nottingham NG7 2RD,

UK

Full list of author information is available at the end of the article
}

(c) The Author(s). 2020 Open Access This article is distributed under the terms of the Creative Commons Attribution 4.0 International License (http://creativecommons.org/licenses/by/4.0/), which permits unrestricted use, distribution, and reproduction in any medium, provided you give appropriate credit to the original author(s) and the source, provide a link to the Creative Commons license, and indicate if changes were made. The Creative Commons Public Domain Dedication waiver (http://creativecommons.org/publicdomain/zero/1.0/) applies to the data made available in this article, unless otherwise stated. 


\section{Introduction}

Approximately $33 \%$ of adults aged over 65 years, and $50 \%$ of adults aged over 80 experience falls each year, with $20 \%$ resulting in injury [1-4]. The National Health Service is estimated to spend $£ 2.3$ billion per year treating falls [5]. The human cost of falls includes injury, declines in physical function and loss of confidence and independence $[3,4]$.

Physical inactivity in older adults results in muscle weakness, poor balance, functional impairment and an increased falls risk [6,7]. Exercise improves muscle strength, balance and physical function and reduces falls rates in older adults by $23 \%$ [8-11]. Therefore, clinical guidelines recommend older adults at risk of falls attend falls prevention exercise programmes [12]. The Falls Management Exercise (FaME) programme contains agespecific strength, balance, cardiovascular and flexibility exercise aiming to improve physical function and reduce falls risk in older adults. The ProAct $65+$ trial showed FaME significantly increased moderate to vigorous physical activity (MVPA) and reduced falls rates in FaME attendees at 12 months, but not at 24 months [13].

The current study developed a multicomponent behaviour change intervention called the Keeping Adults Physically Active (KAPA) programme to encourage the continuation of physical activity (PA) in older adults exiting FaME programmes. Our research aim was to investigate the feasibility and acceptability of the KAPA intervention to the participants. To meet this aim, research objectives investigated attendance and adherence rates to the KAPA programme and evaluated its acceptability via semi-structured interviews and questionnaires. Parameter estimates of MVPA, recruitment and retention rates, research costs, programme fidelity and adverse events were investigated to inform the design of a definitive trial.

\section{Methods}

\section{Study design}

This was a mixed-methods, two-arm, (multisite) cluster randomised feasibility study comparing the KAPA programme with usual care.

\section{Setting}

Participants were recruited from governmentcommissioned-based FaME classes, delivered in the community by leisure service providers within Derby City, Rutland and Leicestershire Counties.

\section{Participants}

There were two types of participants:

1. Community-dwelling FaME programme service users aged 65 years or older.
2. Postural Stability Instructors (PSIs) delivering FaME classes.

All PSIs and FaME class attendees were considered eligible. Participants were ineligible if unable to provide written consent. Participants were withdrawn from the study at their request or if they could not safely engage with PA.

\section{Sample size}

A sample size calculation informed the recruitment targets [14]. We anticipated there would be 12 PSIs, each delivering one FaME class containing 10 participants. With 12 PSIs and 120 participants in 12 classes, and an intra-class coefficient (ICC) of 0.05 [15]; the feasibility study would be able to detect a recruitment rate of $70 \%$ with a $95 \%$ confidence interval (CI) ranging from 60 to $80 \%$.

\section{Recruitment}

Initial recruitment was poor so two recruitment periods were conducted to increase recruitment rates (recruitment strategy 1: January to February 2017 and recruitment strategy 2: June to July 2017). Researchers e-mailed eligible PSIs to provide study information and request their participation. Recruitment strategy 1 took place between weeks 20 and 24 of the original FaME classes. Each recruited PSI provided oral and written study information and an expression of interest slip to the FaME class attendees during their classes. Recruitment strategy 2 took place up to 6 months after the original FaME class completion. Each recruited PSI provided written study information and an expression of interest slip to the participants either during the usual care classes or by phone and post. Researchers received expression of interest slips and met with interested participants to answer questions and obtain written consent.

\section{Randomisation}

PSIs and participants were recruited prior to randomisation. PSIs were randomised in a 1:1 allocation ratio to deliver KAPA or usual care. PSIs were stratified by study centre (2 strata) and randomly allocated within strata. The study statistician computer generated the random allocation. Two PSIs delivering the same FaME class were allocated as one unit. Some PSIs delivered two FaME classes, therefore one class was selected by an independent researcher tossing a coin.

\section{Allocation concealment}

Study arm allocations were placed in numbered sealed opaque envelopes and grouped by stratum. PSIs were chronologically numbered depending on their recruitment date. An independent researcher opened the 
envelopes and documented the PSI's allocation. PSIs and participants were blinded to the group allocation until all participants were recruited. Researchers were not blinded.

\section{Intervention procedures}

KAPA training and mentoring programme procedures

Intervention arm PSIs were trained in motivational interviewing, the KAPA programme and were given a trainee handbook and standard operating procedures. PSIs received up to three, 1-hour, mentoring sessions to support the effective delivery of KAPA.

\section{KAPA intervention arm procedures}

Participants received six sessions of motivational interviewing and behaviour change techniques (BCTs) that aimed to motivate them to keep active. Sessions were delivered within community venues in a group setting by the PSIs. Sessions lasted between 60 and 90 minutes and were delivered over a 6-month period. Participants received a pedometer and a participant manual containing illustrated exercises, worksheets and PA diaries. KAPA was delivered by telephone if a participant was unable to attend sessions. Intervention participants had access to usual care. Table 1 outlines the intervention strategies delivered in each KAPA session.

\section{Usual care arm procedures}

Participants finishing the 24-week commissioned FaME programme were offered usual-care which was a weekly, self-funded, FaME exercise class.

\section{Data collection and outcome measures}

Quantitative data were used to evaluate recruitment, retention, adherence and attendance rates, measures of fidelity, intervention cost, adverse events and PA estimates. Qualitative data were used to evaluate the KAPA programme acceptability. Service providers routinely collected the participants' socio-demographic characteristics and the participants consented to share their data with the researchers.

Baseline research data were collected between January 2017 and July 2017 and post-intervention data between July 2017 and February 2018. All research data were collected at the study sites. Figure 1 depicts the data collection time points and data collected per study arm.

\section{Recruitment and retention rates}

Researchers recorded the number of PSIs and FaME class attendees invited and recruited into the study. Retention rates were recorded as the number of participants remaining in the study at the 6-month time point.
Table 1 Table outlining the intervention strategies delivered in each KAPA session

\begin{tabular}{ll}
\hline Month & Session content \\
\hline 1 & Initial consultation
\end{tabular}

Review current health

Explore knowledge on PA and educate on the PA guidelines

Reflect and compare current PA levels with PA guidelines

Cost-benefit analysis and mental imagery of two alternate futures

Provide information about local PA services

Introduce and demonstrate illustrated exercise booklet

Plan weekly physical activities

Barriers and facilitators of completing the PA plan

Identify people who can provide social support

PA goal setting

Rate commitment and confidence ratings towards meeting goals

Provide and discuss the use of PA diaries and pedometers

Document a signature of commitment

$2 \quad$ Follow-up session 1

Reflect on PA diaries and goal achievement and adapt plans and goals accordingly.

Problem solve high-risk situations and write "if then" plans.

Encourage the use of self-monitoring tools and accessing social support

$3 \quad$ Follow-up session 2:

Reflect on PA diaries, goal achievement, if then plans, and adapt plans and goals accordingly.

Introduce relapse prevention strategies (i.e. monitoring tools, reflecting on past successes, recovering from lapses, planning coping strategies).

Building new habits (i.e. building knowledge of habit formation, discussing poor PA habits, keeping a habit diary)

Rewarding good PA behaviours

Reflecting on enjoyment gained from being more active

\section{4 \& $5 \quad$ Follow-up session 3 \& 4}

Reflect on PA diaries, goal achievement, if then plans, and adapt plans and goals accordingly.

Identifying and planning for possible changes in life circumstances

Identifying plans to over-ride old PA habits

Discussing stress management

Planning for mentally challenging times

$6 \quad$ Follow up session 5

Reflect on PA diaries, goal achievement, if then plans, and adapt plans and goals accordingly.

Reflect on self-regulation skills

Plan how people intend to keep physically active after KAPAs end

Reflect on achievements and give praise

Sign a pledge of commitment

Each component was delivered using a motivational interviewing approach 


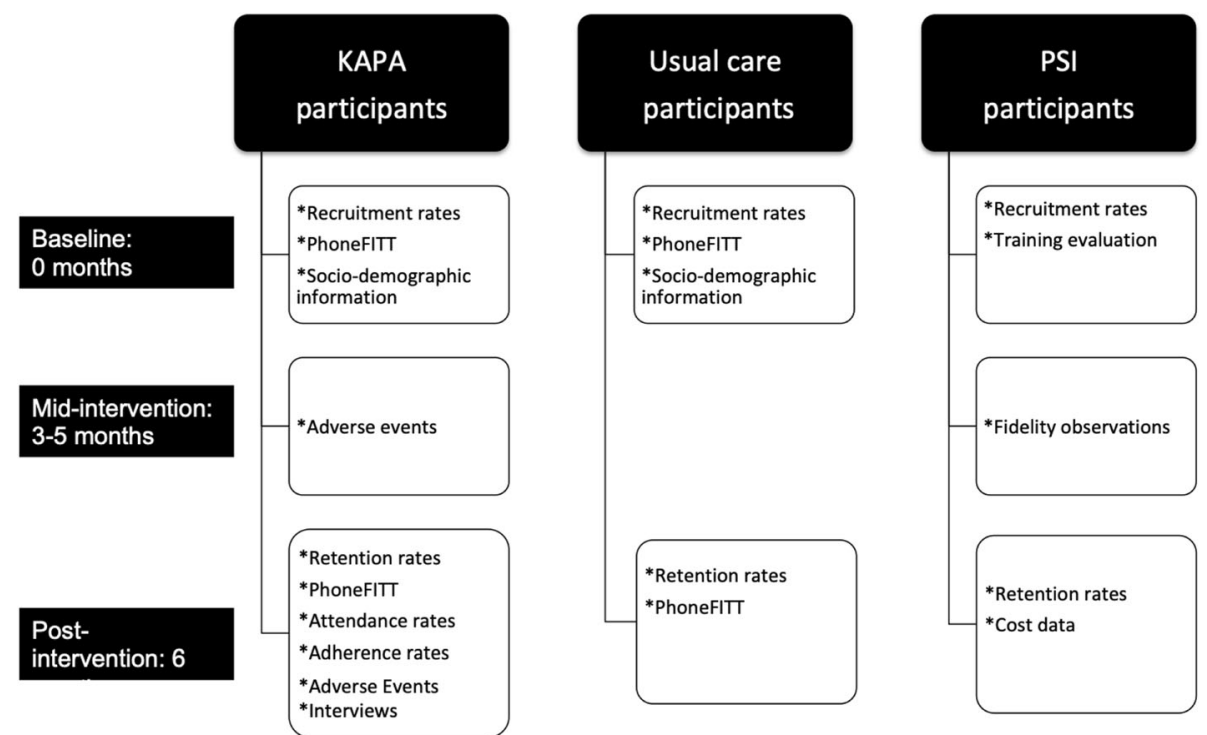

Fig. 1 Data collection time points and data collected per study arm. PhoneFITT is a self-reported PA questionnaire

\section{Measures of feasibility: KAPA participants}

The PSIs documented attendance at each telephone or face-to-face KAPA session in the class registers. Selfmonitoring PA and setting goals were key intervention BCTs and used to measure intervention adherence. The PSIs asked the participants if they had completed their diaries and achieved their goals during each session and recorded the responses in the class registers.

Estimates of MVPA were collected using the PhoneFITT questionnaire. Phone-FITT measures frequency, duration, intensity and type of PA performed. PhoneFITT's reliability and validity has been established by comparing older adults' Phone-FITT scores and accelerometer counts (Spearman's correlation coefficient (95\% $\mathrm{CI})$, ranging from $0.29(0.01,0.53)$ to $0.57(0.34,0.73)$ [16]. The PSIs handed Phone-FITT questionnaires to the participants to self-complete and collected them back at the end of the KAPA/usual care sessions. Participants who stopped attending sessions were posted the questionnaire and a self-addressed envelope.

\section{Measures of feasibility: PSIs}

The trainer handed training evaluation forms to each PSI after the KAPA training to assess its acceptability. Evaluation forms contained questions and response options on 4 and 5-point Likert rating scales relating to the quality and usefulness of the training materials and whether the PSIs were confident to deliver KAPA.

Fidelity of the KAPA programme was ascertained by observations of one initial and follow up session per PSI. Observations lasted the class duration and were recorded on a fidelity checklist investigating the following:
- Health, safety and environment management

- Communication

- Conducting a behaviour analysis

- Reviewing behaviours

- Delivering BCTs

- Introducing and closing sessions

The observer dichotomised items as being achieved or not achieved. PSI adherence with the data collection protocol was measured by whether the class registers were fully complete.

\section{Cost data}

A local government perspective of costing the KAPA programme was used to assess the direct costs incurred. Cost proformas were emailed to, and completed by, the service providers at the 6 -month time point. Cost data included staff salaries, staff travel expenses, administration costs, venue hire, consumables and training day attendee expenses (price year 2017). A researcher recorded the costs incurred to deliver the KAPA training day (venue hire, training manuals, trainer salary and travel expenses).

\section{Adverse events}

A researcher explained the definition of an adverse event to each intervention participant. Participants were given a contact details card and asked to contact the researcher if any adverse event occurred. A researcher telephoned the participants every 3 months to collect data. 


\section{Interviews}

All intervention arm participants were invited to a semistructured interview. Interviews explored their perceptions on the acceptability, benefits and disadvantages of the KAPA programme. Interviews lasted up to $60 \mathrm{mi}$ nutes and took place at the participants' homes or a community location.

\section{Data analysis}

Recruitment, retention, adherence and attendance rates and the training evaluation responses were described using numbers and percentages. Fidelity scores were summed as the total number and percentage of items achieved within each, and across all, criteria.

The median (interquartile range (IQR)) total weekly MVPA and the proportion meeting the governmentrecommended 150 minutes of MVPA per week target were estimated at baseline. The MVPA data were not normally distributed, therefore participants were dichotomised into the proportion undertaking the $\geq 150$ minutes MVPA target. The proportion meeting the MVPA target was compared between study arms using random-effects logistic regression models to estimate the odds ratio and 95\% confidence interval and adjusting for study site and baseline MVPA. A one-way analysis of variance was used to estimate the intraclass correlation coefficient for the proportion meeting the MVPA target, as described by Ridout et al. [17] Baseline data for 4 intervention and 1 usual care participants was missing and not included in any analysis.

Total staff costings over the 6-month period were calculated by the hourly staff salary multiplied by the length of time taken on intervention delivery, travel or administration. Non-salary related costs were summed and multiplied over the intervention period. Consumable costs were summed as one-off costs. The mean cost across all study sites and per participant was estimated and described.

Adverse events were summed and described narratively. Semi-structured interviews were audio-recorded and transcribed verbatim. Transcribed data were handled using NIVO10 software and coded. All interviews were analysed using a framework analysis approach [18].

\section{Results}

\section{Recruitment and retention rates}

Ten PSIs were eligible, including two pairs of PSIs that jointly delivered FaME classes. Ten PSIs and the attendees of eight FaME classes were recruited. Sixtyseven participants within 8 classes were invited into the study and 50 participants $(74.6 \%)$ were recruited $(n=20$ intervention arm, $n=30$ usual care arm).

Twenty-five (83\%) usual care participants provided outcome data at the 6-month time point as five participants were lost to follow-up (reasons unknown). No intervention participants were lost to follow-up and all provided outcome data. Two intervention participants stopped receiving KAPA, one based on GP advice and one whose reasons were unknown. Five (83\%) intervention PSIs and four usual care PSIs provided outcome data. Figure 2 depicts the KAPA participant recruitment flow through the study.

\section{Sociodemographic information}

Table 2 outlines the participants' sociodemographic characteristics and PA levels at baseline.

\section{Attendance rates}

Twenty intervention participants attended 94.2\% ( $n=$ $113)$ of the six available KAPA sessions $(n=120)$. Ninety-seven of 113 sessions were attended face-to-face (78.2\%) and sixteen were attended by phone (21.8\%). Figure 3 depicts the number of participants attending each of the six sessions.

\section{Adherence}

Four participants were $100 \%$ compliant with completing all PA diaries. PA diary adherence data was incomplete for 16 participants (totalling 35\% missing data). Goal attainment data was missing for 17 participants (totalling $37 \%$ missing data); the 3 participants with complete data reported achieving $80 \%$ of their PA goals.

\section{Estimates of MVPA}

The proportion of participants achieving the MVPA target was $56.3 \%$ in the intervention arm and $41.4 \%$ in the usual care arm at baseline. Six-month follow-up data showed the proportion meeting the MVPA target rose in the intervention (62.5\%) and usual care (52.0\%) arms. The odds of reporting meeting the MVPA target were $25 \%$ higher in the intervention than usual care arm, but this did not reach statistical significance (OR 1.25, 95\% CI 0.26 to $5.88 ; p=0.78)$. The ICC for reaching the target MVPA minutes was < 0.001 (95\% CI 0.00 to 0.24 ) Table 3.

\section{Training evaluation}

PSIs reported either "comprehensive" or "adequate" coverage of the theory and practical skills needed to deliver KAPA. All 6 PSIs assigned to delivering the KAPA intervention reported the training and lectures were easy to follow. Three PSIs "agreed" that the learning materials were helpful. All PSIs were "confident" or "very confident" in developing PA plans, reviewing goals and delivering the follow-up sessions. PSIs reported being "confident" or "quite confident" in delivering motivational interviewing and behavioural assessments. 


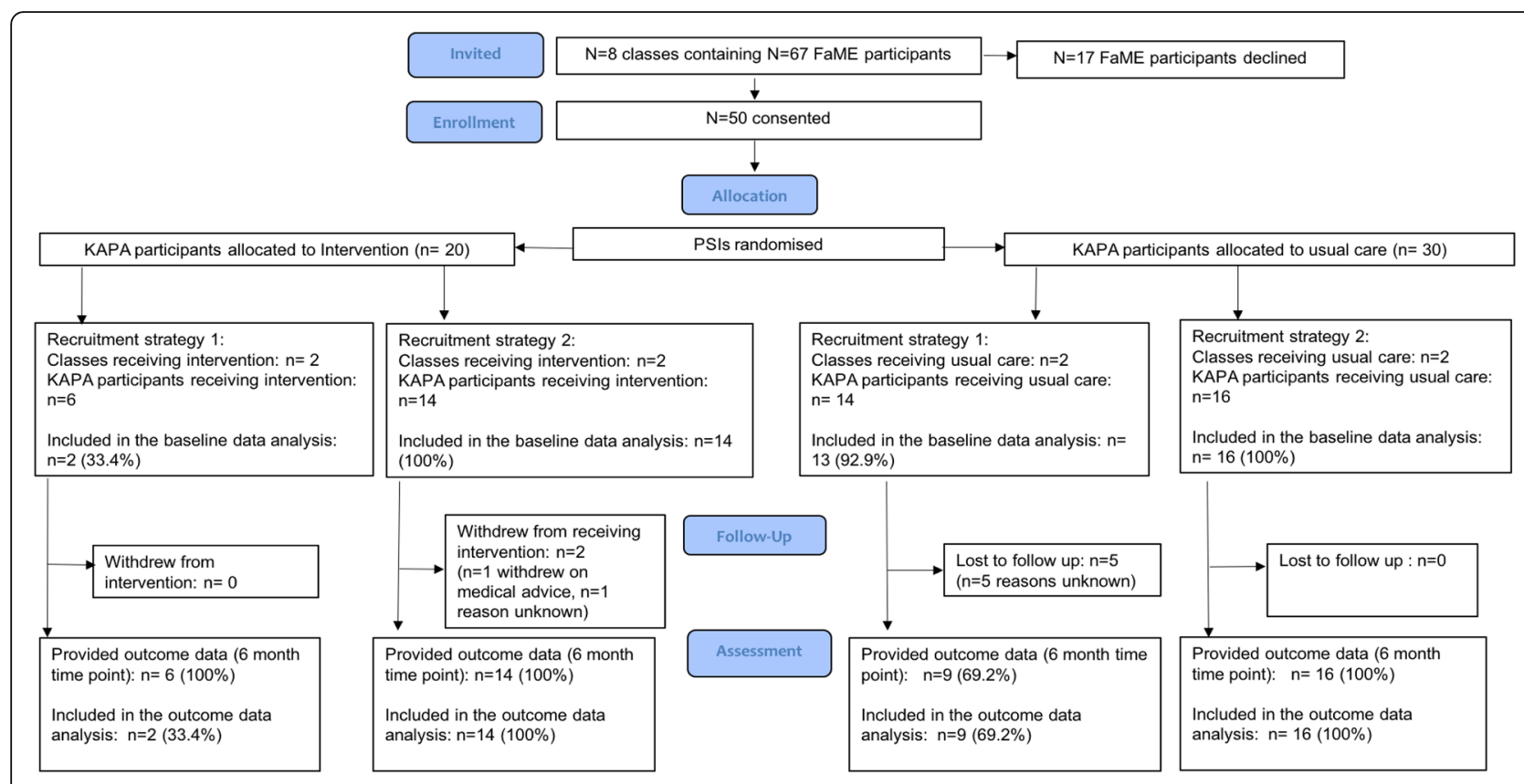

Fig. 2 KAPA participant flow through the KAPA feasibility study

\section{Fidelity observations}

Total fidelity scores achieved across all PSIs remained similar between observation 1 (74\%) and 2 (75\%). Between the first and second observations, PSIs' communication scores (85 to 100\%) and session closing scores (70 to $93 \%$ ) improved. Scores relating to introducing the session (88\% vs $65 \%$ ) and delivering BCTs $(67 \%$ vs $43 \%$ ) reduced. Setting up the environment and health and safety scores were $100 \%$ in all observations.

\section{KAPA study costs}

Total cost of delivering the KAPA intervention was $£ 3$, 987.85 (GBP) and per participant cost was £199.39. Table 4 shows the total KAPA intervention costs incurred.

\section{Adverse events}

One adverse event and two adverse reactions were reported. Table 5 summarises all reported adverse events.

\section{Qualitative data}

Semi-structured interviews were conducted with 16 intervention participants. Emerging themes related to the acceptability of the PA diaries, participant manuals and intervention dosage, satisfaction with the venues and PSIs and the perceived benefits and disadvantages of taking part in the KAPA programme. Table 6 contains quotes supporting the qualitative findings.

\section{Acceptability of completing the diaries and pedometers}

Diary completers believed the diaries focused their mind on their goals and they felt motivated and satisfied by their achievements. Participants who found completing the diaries inconvenient discussed finding the pedometer motivating. A number of participants reported they were still using the pedometers and diaries to motivate them to keep active after KAPA ended.

\section{Acceptability of the participant manuals}

Participants expressed a variety of views on the acceptability of the participant manuals. Numerous participants found the manuals informative and worksheets useful. Yet others found the worksheets repetitive and over complicated and suggested they would be improved if "simplified". All participants believed the illustrated home exercise booklet helped "remind" them how to perform the home exercises.

\section{Acceptability of the intervention duration, frequency and timings}

Most participants felt the intervention duration was "long enough" and the frequency of sessions was "about right" and they would not have benefited from a longer intervention period or more frequent sessions. Running the KAPA programme over a lunchtime was a barrier as many participants wanted to "get back" home for a meal.

\section{Satisfaction with the venues and PSIs}

Participants were highly satisfied with the venues as they were accessible and had good parking and refreshment 
Table 2 KAPA participants' socio-demographic and baseline PA information

\begin{tabular}{|c|c|c|}
\hline & $\begin{array}{l}\text { Intervention arm } \\
n=16\end{array}$ & $\begin{array}{l}\text { Usual care arm } \\
n=29\end{array}$ \\
\hline \multicolumn{3}{|l|}{$\overline{\text { Age }}$} \\
\hline Mean, (SD) & $76.9(7.0)$ & $73.8(6.4)$ \\
\hline \multicolumn{3}{|l|}{ Gender $n(\%)$} \\
\hline Female & $13(81.3)$ & $20(69.0)$ \\
\hline Male & $3(18.7)$ & $9(31.0)$ \\
\hline \multicolumn{3}{|l|}{ Ethnicity $n(\%)$} \\
\hline White British & 15 (93.8) & $29(100)$ \\
\hline Asian Indian & $1(6.3)$ & $0(0.0)$ \\
\hline \multicolumn{3}{|l|}{ Co-morbidities n (\%) } \\
\hline 0 (None) & $1(6.3)$ & $5(17.2)$ \\
\hline 1 & $2(12.5)$ & $7(24.1)$ \\
\hline 2 & $6(37.5)$ & $7(24.1)$ \\
\hline 3 & $2(12.5)$ & $5(17.2)$ \\
\hline 4 & $2(12.5)$ & $3(10.4)$ \\
\hline 5 & $1(6.3)$ & $2(6.9)$ \\
\hline 6 or more & $2(12.5)$ & $0(0.0)$ \\
\hline IMD n (\%) & $(n=12)$ & $(n=22)$ \\
\hline Quintile 1-most deprived & $0(0.0)$ & $3(13.6)$ \\
\hline Quintile 2 & $2(16.7)$ & $7(31.8)$ \\
\hline Quintile 3 & $2(16.7)$ & $1(4.6)$ \\
\hline Quintile 4 & $1(8.3)$ & $2(9.1)$ \\
\hline Quintile 5-least deprived & $7(58.3)$ & $9(40.9)$ \\
\hline \multicolumn{3}{|l|}{ Education n (\%) } \\
\hline Secondary school (age 15/16) & $10(62.5)$ & $20(69.0)$ \\
\hline Secondary school (age 17/18) & $2(12.5)$ & $0(0.0)$ \\
\hline College & $1(6.3)$ & $6(20.7)$ \\
\hline University & $3(18.8)$ & $3(10.3)$ \\
\hline FRAT score $n(\%)$ & & $(n=28)$ \\
\hline 0 & $5(31.3)$ & $9(32.1)$ \\
\hline 1 & $5(31.3)$ & $7(25.0)$ \\
\hline 2 & $1(6.3)$ & $6(21.4)$ \\
\hline 3 & $5(31.3)$ & $6(21.4)$ \\
\hline \multicolumn{3}{|l|}{ Physical activity } \\
\hline $\begin{array}{l}\text { Total minutes of MVPA—median, } \\
\text { (IQR) }\end{array}$ & $\begin{array}{l}160.0(57.5 \text { to } \\
532.5)\end{array}$ & $\begin{array}{l}46.0(0.0 \text { to } \\
267.0)\end{array}$ \\
\hline \multicolumn{3}{|l|}{ Total MVPA minutes: } \\
\hline 0-149 minutes MVPA $n,(\%)$ & $7(43.8)$ & 17 (58.6) \\
\hline$\geq 150$ minutes MVPA $n,(\%)$ & $9(56.3)$ & $12(41.4)$ \\
\hline
\end{tabular}

Missing baseline data 5 participants, $n=4$ intervention arm, $n=1$ usual care arm

IMD index of multiple deprivation, FRAT Falls Risk Assessment Tool facilities. Participants positively viewed the PSIs personal characteristics and found them motivating, encouraging, helpful and knowledgeable.

\section{Social benefits}

The KAPA programme's main benefit from the view of the participants was the enjoyment gained from interacting with others in a group. Participants discussed feelings of encouragement and motivation from their group and how they enjoyed encouraging others. Participants who lived alone particularly found these opportunities helpful.

\section{Discussion}

\section{Summary of findings}

The KAPA intervention was feasible to deliver within community-based PA services, and acceptable to older people exiting FaME classes. Due to small class sizes and PSI numbers the target of recruiting 120 participants was not achieved. Ninety percent of participants received the KAPA programme until the 6-month time point and attendance rates were high (94\%), suggesting it was feasible to attend. Participant adherence with the PA diaries and goals could not be ascertained due to missing data. Fidelity results suggest that PSIs communicated well but many BCTs were not delivered. A higher proportion of the intervention arm reported achieving the MVPA target, but this did not reach statistical significance.

\section{Interpretation of the findings}

PA studies in older people often do not recruit enough participants to meet sample size requirements [19-26]. Only one FaME class per PSI was selected which limited the number of classes and participants reached. More PSIs need to be recruited to allow for more classes and participants to be recruited in a definitive trial.

Social activities give older adults enjoyment and the motivation to exercise [25, 27-31]. Similarly, the KAPA participants reported enjoying interacting with their peers, which motivated them to attend the KAPA sessions. Therefore, fostering social networks may be an integral component in interventions aimed at older adults. Substantial evidence shows that older adults remain active in response to self-monitoring and goal-setting activities [20, 21, 24-26, 32-44]. Comparably, KAPA participants often spoke of the motivation gained by meeting their goals and monitoring their activity. Similar to other PA studies [25, 40], we had a mixed reception to the manual and writing activities whereby some participants found them helpful and others did not. Thus, writing activities may need to be tailored to individual participants to improve programme acceptability.

Authors investigating PA maintenance programmes report an average of $20 \%$ of participants experience 


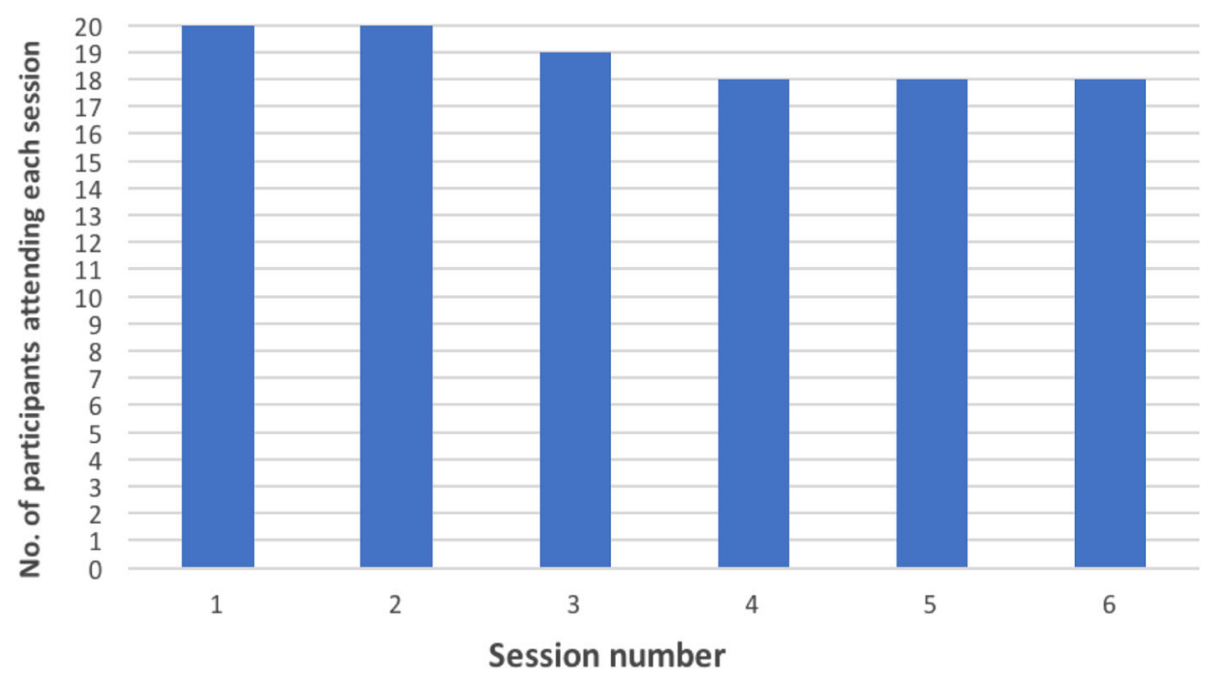

Fig. 3 The number of participants attending each of the six KAPA intervention sessions

adverse events $[25,40]$. Our $15 \%$ adverse event rate is similar to other studies, suggesting the KAPA intervention does not require major modification to reduce potential harm.

\section{Strengths and Limitations}

Retention and attendance rates were high showing that the KAPA intervention has good potential to retain the participant numbers needed to maintain statistical power in a definitive trial. We aimed to assess intervention adherence by measuring the proportion of people completing the PA diaries and achieving their PA goals. However, we were unable to draw conclusions about adherence due to a substantial amount of missing data. It is unknown why such a large amount of data was missing. To help overcome data collection deficiencies a definitive trial would benefit from the research team collecting the adherence data.

The point estimate of the KAPA intervention potential treatment effect (maintenance of PA) remains unknown as seven of the eight study sites were offered self-funded FaME classes as part of usual care. This likely contributed to MVPA levels being maintained. To reduce the possibility of type 2 errors future trials assessing the effects of maintenance interventions should avoid such contamination.

The Phone-FITT questionnaire is a validated tool to collect self-reported PA data using an interview approach [16]. The KAPA feasibility study did not use the tool in its validated form as the study participants selfcompleted the Phone-FITT questionnaire, and it is unclear whether using a none interview approach affected its validity or reliability of the PA outcomes [45]. Therefore a definitive trial should collect Phone-FITT data using an interview approach and quantify the results using validated methods [16].

The recruitment period was extended, resulting in a 6month intervention delivery delay to many participants. Treatment effects of exercise interventions (such as FaME) are known to diminish after the intervention is discontinued $[33,46]$. Therefore, the absolute increases in MVPA may be greater in the participants receiving a delayed intervention as PA may have reduced after FaMEs end and later spiked in response to KAPA. In a definitive trial, all participants should receive the KAPA intervention within the same time window and immediately after the end of the FaME classes to reduce baseline PA differences and maximise potential effects.

Table 3 The proportion of participants and adjusted odds ratios for achieving 150 minutes of MVPA by study arm

\begin{tabular}{lllll}
\hline 6-month time point & $\begin{array}{l}\text { Intervention arm }(n=16) \\
n(\%)\end{array}$ & $\begin{array}{l}\text { Usual care arm }(n=25) \\
n(\%)\end{array}$ & OR & $95 \% \mathrm{Cl}$ \\
\hline Total MVPA minutes & & $12(48.0)$ & Ref & \\
$0-149$ minutes MVPA & $6(37.5)$ & $13(52.0)$ & 1.25 & 0.26 to 5.88 \\
$\geq 150$ minutes MVPA & $10(62.5)$ & 0.78 \\
\hline
\end{tabular}

Missing values $n=4$ intervention group; $n=5$ usual care group 
Table 4 Total costs for delivering the KAPA intervention

\begin{tabular}{|c|c|c|}
\hline \multicolumn{3}{|l|}{ Service provider costing } \\
\hline \multirow[t]{2}{*}{ Category } & \multicolumn{2}{|c|}{$\begin{array}{l}\text { KAPA intervention ( } n=20) \\
\text { No. of sessions delivered across the } 4 \\
\text { intervention sites: } 52\end{array}$} \\
\hline & Total cost $(£)$ & $\begin{array}{l}\text { Average cost } \\
\text { per item per } \\
\text { site }(£)\end{array}$ \\
\hline \multicolumn{3}{|l|}{ Setup costs: KAPA training } \\
\hline $\begin{array}{l}\text { Attending KAPA training and } \\
\text { mentoring sessions (PSI wages) }\end{array}$ & 835.90 & 208.98 \\
\hline Travel expenses (PSI) & 18.00 & 4.50 \\
\hline Training manuals & 50.58 & 12.65 \\
\hline Venue hire & 140.00 & 35.00 \\
\hline Trainer wage & 420.00 & 105.00 \\
\hline Travel expenses (trainer) & 32.40 & 8.10 \\
\hline $\begin{array}{l}\text { Attending KAPA training and } \\
\text { mentoring sessions (PSI wages) }\end{array}$ & 835.90 & 208.98 \\
\hline Travel expenses (PSI) & 18.00 & 4.50 \\
\hline \multicolumn{3}{|l|}{ Reoccuring delivery costs } \\
\hline \multicolumn{3}{|l|}{ Staff salary } \\
\hline $\begin{array}{l}\text { Intervention delivery time } \\
\text { (face to face and by phone) }\end{array}$ & 1208.34 & 302.09 \\
\hline Administration time & 386.82 & 96.71 \\
\hline Travelling time to classes & 171.84 & 42.96 \\
\hline $\begin{array}{l}\text { Travel expenses } \\
\text { (i.e. petrol and parking) }\end{array}$ & 54.00 & 13.50 \\
\hline Venue hire & 345.00 & 86.25 \\
\hline Refreshments & 30.00 & 7.50 \\
\hline Administration consumables & 2.24 & 0.56 \\
\hline Telephone usage & 94.45 & 23.61 \\
\hline $\begin{array}{l}\text { Pedometers and participant } \\
\text { manuals }\end{array}$ & 198.28 & 49.57 \\
\hline Total intervention cost & $£ 3,987.85$ & \\
\hline Total per participant & $£ 199.39$ & \\
\hline
\end{tabular}

\section{Generalisability}

In the UK, FaME classes are provided within many different settings including healthcare settings [47]. Whilst we know that the FaME programme is effective regardless of setting, we do not know whether FaME and KAPA being delivered in a leisure service setting increase the likelihood of maintaining PA. Thus, the study results cannot be generalised into classes being delivered
Table 6 Quotes supporting the qualitative findings Acceptability of completing the diaries

"Well there were odd days obviously when I was out, but it got done on a daily basis it never got left until the next day" PT03_Female, 69_ site 1

"The big thing I found the most helpful was the physical activity diaries, because you could take a look at the end of the week, it felt good that I had done better last week than the week before..." PT03_Female, 69_site 1

"I thought it was a bit of a pain filling in you know the sort of diary" PT02_Female, 76_site 1

"Oh yes, I will continue the book because like I say I think it focuses your mind on how many steps you're doing and exactly what you're doing or not doing." PT08_Female, 67_site 3

“The only disadvantage is one doesn't like filling in forms but that was really all." PT12_Male, 85_site 4

Acceptability of the participant manuals

"The manual was very good, very instructive" PT02_Female, 76_site 1 "I found it useful that we got the exercise programme printed out for us, and when you come to do your exercises at home then you have got something to remind you" PT10_Female, 79_ site 3

"It seemed over complicated... but to have it simplified we thought."

PT11_Male, 73_site 4

Acceptability of the intervention duration, frequency and timings

"I think a month is about right, weekly but weekly would be a chore" PT07_Female, 84_site 3

"They finish at 1, you sort of want to get back to have a meal really ..." PT01_Male, 82_site 1

Satisfaction with the venues and PSIs

"Well I think it is a good facility, you know everything is there that you need. The space, it is clean, there is toilets, coffee and nice people ... just everything about it is just right." PT11 Male, 73 site 4

"Well you have got a very good instructor, I think he did a good job... if you came up with a problem, he suggested how you could get around it." PT01_Male, 82_site 1

Social benefits

"Being a group. Yes. And the fact that we see one person is doing something, and if another one is ill and can't do it, we are there encouraging them that they are doing the best they are able to within their abilities. So, they don't feel that they are not achieving anything because we are encouraging them." PT07_Female, 83_site 3

"Because one of the important features of those classes was the social interaction with other people." PT12_Male, 85_site 4

within healthcare settings. KAPA participants selected themselves into FAME classes and into KAPA. Therefore, it is possible that the people needing KAPA the most were not reached. To help improve the study findings generalizability, future trials should aim to recruit older adults from a wider geographical area and diversity of settings.

Table 5 Description of adverse events

\begin{tabular}{|c|c|c|c|c|c|}
\hline & \multirow[t]{2}{*}{ Description } & \multirow{2}{*}{$\begin{array}{l}\text { Place of event } \\
\text { During KAPA activities }\end{array}$} & \multicolumn{3}{|c|}{ Adverse event category } \\
\hline & & & Adverse event & Adverse reaction & $\overline{\text { Relation to KAPA }}$ \\
\hline 1. & Walking injury. Knee osteoarthritis exacerbation. & Yes & No & Yes & Possibly \\
\hline 2. & Fall in exercise class. Skin graze. & Yes & Yes & No & Definitely \\
\hline 3. & Walking injury. Plantar-fasciitis. & Yes & No & Yes & Possibly \\
\hline
\end{tabular}




\section{Implications for progression to a definitive trial}

A definitive trial should anticipate class and participant numbers based on our findings and should aim to recruit more study sites. Using PSIs to collect adherence data was an ineffective strategy. Yet, diary return rates to researchers are 50 to $60 \%$ in older adults [48]. A possible solution could be for PSIs to collect adherence sheets during the KAPA sessions to forward to the research team.

Fidelity results show the PSIs did not deliver the BCTs as intended. Training evaluation outcomes suggest some PSIs were only "quite confident" in delivering the BCTs which may have affected fidelity. Fidelity improves when monitoring and feedback loops are built into interventions [49-51]. A definitive trial could improve fidelity by feeding back provider performance for training purposes.

Accurately measuring PA is important to assess intervention effectiveness [45]. Self-reported PA is less reliable compared with objectively measured PA [45]. Especially in older adults who are known to overestimate MVPA as a result of poor PA recall and social desirability bias $[44,52,45]$. MVPA accuracy is optimised via accelerometers but there are implications relating to increased research costs and time which would need to be considered when designing a definitive trial $[43,53]$. Additionally, it would be most ideal to compare KAPA against a no-exercise control group to allow for the full effect of KAPA to be investigated.

Interventions are unlikely to be effective if recipients find components unacceptable [54].

Therefore, the KAPA intervention in its present form may benefit from being adapted using the participant perspectives prior to testing in a definitive trial [54].

\section{Conclusion}

The KAPA intervention is feasible to deliver within community PA services. Attendance and retention rates were high suggesting KAPA is acceptable to attend. Overall, participants found KAPA acceptable, but the written materials would be better received if simplified. Illustrated home exercises and PA monitoring tools encouraged the participants to keep active. It is important for older adults exiting FaME programmes to remain physically active so as to maintain the positive health benefits gained. Therefore, a full-scale trial needs to recruit an adequate number of FaME classes to sufficiently power an RCT to assess whether KAPA results in a significant effect on maintaining PA.

\section{Abbreviations}

BCTs: Behaviour change techniques; Cl: Confidence interval; FaME: Falls Management Exercise; FRAT: Falls Risk Assessment Tool; GBP: Great British pounds; ICC: Intra-class coefficient; IMD: Index of multiple deprivation; IQR: Interquartile range; KAPA: Keeping Adults Physically Active; MVPA: Moderate to vigorous physical activity; PA: Physical activity; PSIs: Postural stability instructors

\section{Acknowledgements}

We would like to say a special thanks to all the participants and PSIs who participated in this study.

\section{Authors' contributions}

SA contributed to the study design and set up and managed the trial, collected and analysed data and drafted the manuscript. EO, DK, PL and MJ contributed to the study design, interpretation of data and revision of the manuscript. EO and DK supervised the analyses. DK and PL were the clinical leads of the study. EO was the study chief investigator. The author(s) read and approved the final manuscript.

\section{Funding}

This article presents independent research funded by the University of Nottingham and the National Institute for Health Research School of Primary Care Research (NIHR-SPCR). The views expressed are those of the author(s) and not necessarily those of the NIHR, NHS or the Department of Health.

\section{Availability of data and materials}

The datasets used and analysed during the current study are available from the corresponding author on reasonable request.

\section{Ethics approval and consent to participate}

Ethical approval was obtained from the London-Chelsea Health Research Authority REC (REC reference: 16/LO/0396) in January 2017. The study protocol can be found on ClinicalTrials.gov (NCT03824015).

\section{Consent for publication}

Not applicable.

\section{Competing interests}

The authors declare that they have no competing interests.

\section{Author details}

${ }^{1}$ Division of Primary Care, University of Nottingham, Nottingham NG7 2RD, UK. ${ }^{2}$ Division of Rehabilitation, Ageing and Wellbeing, University of Nottingham, Nottingham, UK.

Received: 1 August 2019 Accepted: 10 February 2020

Published online: 07 March 2020

References

1. Campbell AJ, Reinken J, Allan BC, Martinez GS. Falls in old age: a study of frequency and related clinical factors. Age Ageing. 1981;10(4):264-70.

2. O'Loughlin JL, Robitaille Y, Boivin JF, Suissa S. Incidence of and risk factors for falls and injurious falls among the community-dwelling elderly. Am J Epidemiol. 1993;137(3):342-54.

3. Public-Health-England. Falls and fracture consensus statement: Supporting commissioning for prevention. In: England PH, editor. London; 2017.

4. Rubenstein LZ. Falls in older people: epidemiology, risk factors and strategies for prevention. Age Ageing. 2006;35(Suppl 2):ii37-41.

5. NICE. Physical activity: exercise referral schemes [NICE guideline PH54]. In: Excellence NIfC, editor:; 2014.

6. World Health Organization. WHO global report on falls prevention in older age. Geneva: World Health Organization; 2008

7. Lloyd BD, Williamson DA, Singh NA, et al. Recurrent and injurious falls in the year following hip fracture: a prospective study of incidence and risk factors from the Sarcopenia and Hip Fracture study. J Gerontol A Biol Sci Med Sci. 2009;64(5):599-609.

8. Latham NK, Bennett DA, Stretton CM, Anderson CS. Systematic review of progressive resistance strength training in older adults. J Gerontol A Biol Sci Med Sci. 2004:59(1):48-61.

9. Cadore EL, Rodriguez-Manas L, Sinclair A, Izquierdo M. Effects of different exercise interventions on risk of falls, gait ability, and balance in physically frail older adults: a systematic review. Rejuvenation Res. 2013;16(2):105-14.

10. de Kam D, Smulders E, Weerdesteyn V, Smits-Engelsman BC. Exercise interventions to reduce fall-related fractures and their risk factors in individuals with low bone density: a systematic review of randomized controlled trials. Osteoporos Int. 2009;20(12):2111-25. 
11. Sherrington C, Fairhall NJ, Wallbank GK, et al. Exercise for preventing falls in older people living in the community. Cochrane Database Syst Rev. 2019;1: CD012424.

12. A Recipe for Care - Not a Single Ingredient. In: Department-of-Health, editor. London; 2007.

13. Iliffe $S$, Kendrick D, Morris $R$, et al. Multicentre cluster randomised trial comparing a community group exercise programme and home-based exercise with usual care for people aged 65 years and over in primary care. Health Technol Assess 2014; 18(49): vii-xxvii, 1-105.

14. Richards D, Hallberg I. Complex Interventions in Health. An overview of research methods. London: Routledge; 2015.

15. Elley CR, Kerse N, Chondros P, Robinson E. Intraclass correlation coefficients from three cluster randomised controlled trials in primary and residential health care. Aust N Z J Public Health. 2005;29(5):461-7.

16. Gill DP, Jones GR, Zou GY, Speechley M. The Phone-FITT: a brief physical activity interview for older adults. J Aging Phys Act. 2008;16(3):292-315.

17. Ridout MS, Demetrio CG, Firth D. Estimating intraclass correlation for binary data. Biometrics. 1999;55(1):137-48.

18. Braun V, Clarke V. Using thematic analysis in psychology. Qual Res Psychol. 2006;3(2):77-101.

19. Harris T, Carey I, Victor C, Adams R, Cook D. Optimising recruitment into a study of physical activity in older people: a randomised controlled trial of different approaches. Age Ageing. 2008;37(6):659-65.

20. von Bonsdorff MB, Leinonen R, Kujala UM, et al. Effect of physical activity counseling on disability in older people: a 2-year randomized controlled trial. J Am Geriatr Soc. 2008;56(12):2188-94.

21. Teri L, McCurry SM, Logsdon RG, Gibbons LE, Buchner DM, Larson EB. A randomized controlled clinical trial of the Seattle Protocol for Activity in older adults. J Am Geriatr Soc. 2011;59(7):1188-96.

22. Morey MC, Peterson MJ, Pieper CF, et al. The Veterans Learning to Improve Fitness and Function in Elders Study: a randomized trial of primary care-based physical activity counseling for older men. J Am Geriatr Soc. 2009;57(7):1166-74.

23. Morey MC, Ekelund C, Pearson M, et al. Project LIFE: a partnership to increase physical activity in elders with multiple chronic illnesses. J Aging Phys Act. 2006;14(3):324-43.

24. Elley CR, Kerse N, Arroll B, Robinson E. Effectiveness of counselling patients on physical activity in general practice: cluster randomised controlled trial. BMJ. 2003:326(7393):793

25. Dubbert PM, Cooper KM, Kirchner KA, Meydrech EF, Bilbrew D. Effects of nurse counseling on walking for exercise in elderly primary care patients. J Gerontol A Biol Sci Med Sci. 2002;57(11):M733-40.

26. Rydwik E, Lammes E, Frandin K, Akner G. Effects of a physical and nutritional intervention program for frail elderly people over age 75. A randomized controlled pilot treatment trial. Aging Clin Exp Res. 2008;20(2):159-70.

27. Taylor AH, Cable NT, Faulkner G, Hillsdon M, Narici M, Van Der Bij AK. Physical activity and older adults: a review of health benefits and the effectiveness of interventions. J Sports Sci. 2004;22(8):703-25.

28. Bunn F, Dickinson A, Barnett-Page E, Mclnnes E, Horton K. A systematic review of older people's perceptions of facilitators and barriers to participation in falls-prevention interventions. Ageing Soc. 2008;28:449-72.

29. Stevens M, Lemmink KA, van Heuvelen MJ, de Jong J, Rispens P. Groningen Active Living Model (GALM): stimulating physical activity in sedentary older adults; validation of the behavioral change model. Prev Med. 2003;37(6 Pt 1):561-70.

30. Dye CJ, Wilcox S. Beliefs of low-income and rural older women regarding physical activity: you have to want to make your life better. Women Health. 2006:43(1):115-34.

31. Hawley-Hague H, Horne M, Campbell M, Demack S, Skelton DA, Todd C. Multiple levels of influence on older adults' attendance and adherence to community exercise classes. Gerontologist. 2014;54(4):599-610.

32. Khan KM, Weiler R, Blair SN. Prescribing exercise in primary care. BMJ. 2011 ; 343:d4141.

33. Hobbs N, Godfrey A, Lara J, et al. Are behavioral interventions effective in increasing physical activity at 12 to 36 months in adults aged 55 to 70 years? A systematic review and meta-analysis BMC Med. 2013;11:75

34. Azizan A, Justine M, Kuan CS. Effects of a behavioral program on exercise adherence and exercise self-efficacy in community-dwelling older persons. Curr Gerontol Geriatr Res. 2013;2013:282315.

35. Voukelatos A, Merom D, Sherrington C, Rissel C, Cumming RG, Lord SR. The impact of a home-based walking programme on falls in older people: the Easy Steps randomised controlled trial. Age Ageing. 2015;44(3):377-83.
36. Pahor M, Blair SN, Espeland M, et al. Effects of a physical activity intervention on measures of physical performance: Results of the lifestyle interventions and independence for Elders Pilot (LIFE-P) study. J Gerontol A Biol Sci Med Sci. 2006:61(11):1157-65.

37. Opdenacker J, Boen F, Coorevits N, Delecluse C. Effectiveness of a lifestyle intervention and a structured exercise intervention in older adults. Prev Med. 2008:46(6):518-24

38. Luten KA, Reijneveld SA, Dijkstra A, de Winter AF. Reach and effectiveness of an integrated community-based intervention on physical activity and healthy eating of older adults in a socioeconomically disadvantaged community. Health Educ Res. 2016:31(1):98-106.

39. Jancey JM, Lee AH, Howat PA, Burke L, Leong CC, Shilton T. The effectiveness of a walking booster program for seniors. American journal of health promotion : AJHP. 2011;25(6):363-7.

40. Harris T, Kerry SM, Victor CR, et al. A primary care nurse-delivered walking intervention in older adults: PACE (pedometer accelerometer consultation evaluation)-Lift cluster randomised controlled trial. PLoS Med. 2015;12(2): e1001783.

41. Duru OK, Sarkisian CA, Leng M, Mangione CM. Sisters in motion: a randomized controlled trial of a faith-based physical activity intervention. J Am Geriatr Soc. 2010;58(10):1863-9.

42. Buman MP, Giacobbi PR Jr, Dzierzewski JM, et al. Peer volunteers improve long-term maintenance of physical activity with older adults: a randomized controlled trial. J Phys Act Health. 2011:8(Suppl 2):S257-66.

43. Chase JA. Interventions to Increase Physical Activity Among Older Adults: A Meta-Analysis. Gerontologist. 2015:55(4):706-18.

44. Chase JA. Physical activity interventions among older adults: a literature review. Res Theory Nurs Pract. 2013;27(1):53-80.

45. Prince SA, Adamo KB, Hamel ME, Hardt J, Connor Gorber S, Tremblay M. A comparison of direct versus self-report measures for assessing physical activity in adults: a systematic review. Int J Behav Nutr Phys Act. 2008;5:56.

46. Muller-Riemenschneider F, Reinhold T, Nocon M, Willich SN. Long-term effectiveness of interventions promoting physical activity: a systematic review. Prev Med. 2008;47(4):354-68.

47. NICE. Falls in older people: assessing risk and prevention (Clinical guideline [CG161]). In: Excellence NIfC, editor. London; 2013

48. Iliffe $S$, Kendrick D, Morris $R$, et al. Multi-centre cluster randomised trial comparing a community group exercise programme with home based exercise with usual care for people aged 65 and over in primary care: protocol of the ProAct 65+ trial. Trials. 2010;11:6.

49. Breitenstein SM, Gross D, Garvey CA, Hill C, Fogg L, Resnick B. Implementation fidelity in community-based interventions. Res Nurs Health. 2010;33(2):164-73.

50. Carroll C, Patterson M, Wood S, Booth A, Rick J, Balain S. A conceptual framework for implementation fidelity. Implement Sci. 2007;2:40.

51. Borrelli B. The Assessment, Monitoring, and Enhancement of Treatment Fidelity In Public Health Clinical Trials. J Public Health Dent. 2011;71(s1):S52-63.

52. Tucker JM, Welk GJ, Beyler NK. Physical activity in U.S.: adults compliance with the Physical Activity Guidelines for Americans. Am J Prev Med. 2011. 40(4):454-61.

53. Murphy SL. Review of physical activity measurement using accelerometers in older adults: considerations for research design and conduct. Prev Med. 2009:48(2):108-14.

54. Yardley L, Ainsworth B, Arden-Close E, Muller I. The person-based approach to enhancing the acceptability and feasibility of interventions. Pilot Feasibility Stud. 2015;1:37.

\section{Publisher's Note}

Springer Nature remains neutral with regard to jurisdictional claims in published maps and institutional affiliations. 